\title{
ONLINE GRADUATE STUDY HEALTH CARE LEARNERS' PERCEPTIONS OF GROUP WORK AND HELPFUL INSTRUCTIONAL BEHAVIORS
}

\author{
KIM BERGERON BA, MHST (Candidate) \\ Research Assistant \\ By \\ SHERRI MELROSE Phd, RN \\ Assistant Professor \\ Centre for Nursing and Health Studies, Athabasca University, Athabasca, Alberta, Canada \\ ABSTRACT
}

Participating in small group activities has emerged as a trend in online learning events. However, little is known about how graduate students experience online group work and what instructional behoviors are perceived as helpful during the group process. This article discusses a qualifotive research project that reveded how online health care professionals in two graduote studies programs valued knowing their facilitator wos consistently present and ovallable. The project was framed from a constructivist theoretical perspective and a descriptive research design. Participants were health care practitioners who graduated from a Moster of Nursing or Master of Healih Studles program offered exclusively through a WebCr online environment. Data sources included two focus groups and ten individual audio-tape recorded transcribed interviews. The dato was analyzed for themes by two researchers and confirmed with participants through ongoing member checking. The following strategies for creating a safe and engaging online learning climate for members of small project groups are presented. 1) Creafe groups intentionally. 2) intervene with non-contributing members. 3) Measure individual contributions.

\section{INTRODUCTION}

Small group-based teaching approaches can stimulate active and engaged participation among higher education learners. In online graduate study classrooms, professional adult students roturning to formal learning events can be expected to benefit from opportunities to collaborate with their colleagues on required course projects. However, participation in small group work can be a bittersweet experience. Leaners may not find all group work satisfying. Educational research examining learners' experiences with group work and the kinds of instructional strategies that learners themselves perceive as beneficial during their small group work is limited. This article describes findings from a naturalistic study that investigated instructional behaviors that online health care students did believe were helpful and that facilitated cohesive group processes

Participants in the study were graduates of either the Master of Nursing (MN) or Master of Health Studies (MHST) programs offered through Athabasca University, Athabasca. Alberta, Canada. While students enrolled in the MN program hold undergraduate degrees in nursing, those in the MHST program come from nursing, physiotherapy, occupational health, dietetics, medicine and other health care disciplines. Both male and female students are enrolled in these graduate study programs and are required to have practiced in their field for at least two years. Graduates of the 2005 class were predominantly women and lived all across Canoda as well as in a variety of other countries. Course work in the MN and MHST programs is completed exclusively online using a WebCt course management system. Therefore, convocation ceremonies at the university campus were the first opportunity for students in these programs to meet their classmates and instructors. Data for the present research was gathered during the time students were together for convocation ceremonies.

The primary medium for communication, instruction and assessment in the MN and MHST programs is asynchronous text-based threaded discussions within a WebCT environment. In most courses, cohorts of approximately twenty students led by one instructor progress through a study guide identifying a series of readings, discussion questions and learning activities during a fourteen week time frame. These learning activities can include project groups of four or five students participating in an online 


\section{RESEARCH PAPERS}

group work assignment.

\section{Literature Review}

Scholars in the field of higher education hove consistently supported the belief that creating collaborative group work projects for students increases their engagement satisfaction, scope, depth and retention of knowledge (Davis, 1993: Hativa \& Goodyear, 2002; Mckeachie \& Hofer, 2002; Ramsden, 2003), In virtual classrooms. frameworks emphosizing leamer engagement through meaningful peer group interaction are widely accepted (Anderson, \& Elloumi, 2004; Bates \& Poole, 2003; Chickering \& Gamson, 1991; Collison, Elbaum, Haavind \& Tinker, 2000; Keorsley \& Shneideman, 1998).

And yet, reports from a variety of disciplines suggest that, with the absence of verbal and non-verbal communication cues in asynchronous online graduate classrooms, facilitating successful learner-to leaner interaction is seldom straightforward. Exploring interactivity omong professionals returning to online graduate study in a Human Resources Development program, Ehrlich (2002) identified that students' felt anxiety about grades and consistently needed immediate feedback and guidance. Exploring how teams worked together in an online Moster of Business Administration program Gabriel and MacDonald (2002) noted that students' supplemented the asynchronous communication opportunities provided for them in the course with personal or telephone meetings. Exploring colloboration in an online Moster of Education program, Agostinho, Lefoe \& Hedberg (1997) posited that students had little incentive to collaborate with peers when the learning activities were not linkod to their individual assessment. And, exploring cross-disciplinary team building with graduate students in Engineering and the Social Sciences, Murray and Lonne (2006) called for early identification and intervention of problematic group dynamics.

In their comprehensive review of research identifying pitfalls for social interaction in computer-supported collaborative learning, Kreijns, Kirschner, \& Jochems (2003) urged educators not to assume that participants will socially interact simply because the environment makes it possible and not to neglect the social and psychological dimensions of the desired interactions. Clearly, in order to afford students the many benefits of online group work, graduate study educators need practical facilitation strategies to promote successful small group experiences. This article voices the suggestions and reflections that graduates of two health care masters programs can contribute to this ongoing discourse.

\section{The Research Approach}

This project was fromed from a constuctivist theoretical perspective (Kelly, 1955; Piaget, 1954; Wgotsky, 1978) in that knowledge is believed to be constructed through an individual's interactions with social processes and contexts. The research design was descriptive and the findings a case study representation of two health care graduate programs at an open Canadian Distance Education University. The work was guided by the questions: what issues do online graduate leamers face when working in groups; and what instructional behaviors are helpful in addressing these issues.

Dato sources were collected in person and included two focus groups and ten audio tape-recorded transcribed interviews. Content from these dota sources were analyzed first independently and then collaboratively by the researchers. The transcripts were thoroughly read and re-read and a systematic process of content analysis was developed (Denzin \& Lincoln, 1994; Lincoln \& Guba, 1985) to create a categorization and coding scheme leading to themes. Trustworthiness was established through ongoing 
RESEARCH PAPERS

interaction and member checking with participants to ensure authenticity. To ensure anonymity, pseudonyms were used when participants' comments are reported verbatim. Full ethical approval was granted from the Athabasca University Ethics Committee and all participonts gave informed consent.

The program of research was first initiated with an exploration of online graduate students' help-seeking behaviors (Melrose, Shapiro \& Lavallie, 2005). Second, when it became apparent that students' valued teaching strategies that demonstrated immediacy and found them helpful, the concept of immediacy was examined in depth (Melrose \& Bergeron, in press). Third, in response to students' belief that their primary source of help was other students in their class, strategies to facilitate student interaction were described (Melrose, in press). Fourth, within the process of investigating leamers' experiences with helpful and immediate instructional behaviors and their interactions with one another, issues related to working in groups emerged. The present discussion elaborates on specific instructional behaviors that participants appreciated when they were required to work in small groups.

The following three strategies emerged as themes when analyzing the interview and focus group dato collected from and confirmed with students who successfully completed their graduate studies online. The strategies represent students' perceptions of kcy areas where instructional help was needed to facilitate successful group project work. The first strategy was to create groups intentionally. The second strategy was to intervene with non-contributing members. The third strategy was to measure individual contributions.

\section{Findings}

Strategrone: Creale Groups intentionally

When the health care professionals in this project reflected on instructional behaviors that were helpful to them during their group project assignments, discussions frequently centered on how they came to be in the group. The anxiety of being required to self-select into their groups was apparent in comments such as: "It's tough to ask does anybody want to work with me? You don't know anyone and have just seen names on a list." And: "I don" want to work with someone who just wants to pass." By count, commitment to doing well and ochieving a high grade was mentioned the greatest number of times during the research discussions. As Rannu explained: "If we were successful, it was because there was a commitrnent: if commitment was missing it made it difficult." At the outset, for students who were new to both online learning and graduate study, small group project work was perceived as overwhelming at times.

Intentionally engaging online adult leamers, who may feel anxious, concerned about their grades and unfamiliar with the venue, in small group work activities is not easy. Participants in this research repeatedly emphasized that knowing their instructors were present and available was reassuring. In the process of creating groups, instructors who genuinely projected a message of "I am here if you need me' were considered very helpful. Ashwin commented: "As much as instructors told us to establish norms, establish roles, establish expectations, it should also include. if you get into trouble, you can always come back to me." Students expressed that they did not necessarlly want instructors to provide answers; rather, they found it empowering to arive at their own conclusions. Ann described a memorable professor who stated: "If you need help, I'm here, e-mail me.....just come to me, I'm willing to help you through it. I won't do it for you, but I am willing to help you through it."

Thoughtful composition of who would be in their small groups was important to students. They appreciated 


\section{RESEARCH PAPERS}

instructors who inquired about their experience with online learning, with graduate study, with professional leadership skils, with life experiences; and then applied that information to assign or direct them toward membership in a particular group. The process of seeking to know their students and to usher them toward a sate small group further communicated that instructors were present and availoble.

Students also valued a clear articulation of the relevance of required group work. Knowing they were expected to link the objectives and outcomes of their projects to their practice enhanced personal meaningfulness. Specific rubrics for marking group processes as well as for marking project content were expected. And finally, some participants did express a desire not to work in a group and to have alternate assignment opportunities available.

Strategy Two: intervene with Non-contributing Members

Throughout the data collection, participants all identified experiences where they had been members of poorly functioning groups caused by non-contributing members. Non-contributing members were defined as students who did not contribute to the group process or task, as well as students who only wanted to pass without earning an $\mathrm{A}$ grade, In instances where instructors intervened and dealt with non-contributing members, participants emphasized that this strengthened the group process. But. when instructors did not acknowledge and address the issue, the groups were often unable to progress on their own

Nirmila talked about the differences between addressing the issue in face-to-face groups varsus online groups and in undergraduate versus graduate groups. She shared how, in an undergraduate face-to-face group, asking a non-contributing member: "Is there something going on, because you are not pulling your weight here? Can we help you in another woy?" would be acceptable. However. in a graduate online group, she felt that "... it can be perceived as too assertive."

Zara described the uncentainty she experienced when working with a non-contributing member and commented that she "did not know what to do." Ang felt he "did not have the tools" to resolve the issue. Participants also discussed instances where group members shared their concerns over the phone with one another, "...working around the non-contributing member." Another participant described feelings of "relief" when 0 non-contributing member withdrew from the course, thereby lifting the burden of requiring the group to address the problem. Given that their courses were designed for worldwide online-only delivery, students separated from one another by vast geographic distances are clearly disadvantaged without instructor intervention.

Strotegy Three: Measure individual Contributions

Methods of educational measurement that assess group projects can be controversial. Often, instructors assign the same mark to all members, regardless of individual contributions or the group's level of functioning. For participants in the present research, this was prablematic. Several expressed that this assessment method coused them to question whether they would identify problems within the group. Hui Ying explained: "Everyone gets the same mark, and if you were to say anything. you feel like you're going to be ... docked?" And Sue continued: "There has to be a mechanism where you feel safe to comment about the group and [still know that contributions are] fairly marked."

The research discussions raised questions and musings around whother instructors were actually observing student performance in group work. When instructional intervention was not apparent and both contributing and non-contributing members received equal marks, participants felt frustrated, abandoned by their instructor 


\section{RESEARCH PAPERS}

and they lacked closure with the experience.

\section{Discussion}

The aforementioned three instructional strategies, developed from discussions with professionals who successfully completed their graduate degrees exclusively through a Webcr online course management system, begin to illustrate the kind of facilitation approaches that these groups of learners find helpful. Given these findings, implications for educators include ensuring that student project groups are created thoughtfully and intentionally. Clearly, genuinely communicating that one is present and available and reaching out to understand who students are individually can begin this important process of engagement. Acknowledging non-contributing members and intervening immediately can prevent dysfunction and allow members to focus on positive processes and tasks. And, seeking woys to assess individual contributions that extend beyond simply assigning the same mark to all group members will deepen our understanding of student-centered educational measurement.

Creating small project groups online can be a creative undertaking. Some seminar activities traditionally implemented in face-to-face graduate classrooms can be transferred to online discussion boards. For example, as soon as the course has opened, inviting students to share their own ideas about forming successful groups actively involves them and establishes a climate of shared decision making early in the class. Similarly, asking students to list specific instructional strategies that they have found both helpful and not helpful in previous group experiences displays examples the present group may choose to adapt. Providing opportunities for students to share their interests and expertise before requiring them to join a group reduces anxiety. When possible, offering alternatives to group work, such as completing projects alone or in dyads defuses uncertainty.

As the small groups begin to form, including instructors names in each small group roster communicates their presence. Posting online office hours conveys availability. Welcoming messages within the small group meeting areas encouraging members to contact instructors affirms an open line of communication. Designating 0 formative progress report evaluating small group process mid-way through the project defines a place where issues can be addressed.

Before the small groups begin to work on tasks, calling for discussions about group guidelines establishes a studentgenerated structure for rules and norms. Encouraging brief social interactions stimulates affective connections and feelings of emotional safety. Articulating expectations of what students must do and what instructors will do determines consequences. Presenting short précis of conflict resolution models again illustrates examples the present group may adapt. Clarifying behavior that is unacceptable in the group, such as unexplained missed meetings or task completions, sets the stage for peacetul informed resolution. For example, some groups may elect to dismiss a member in response to an unexplained absence; while others may not. However, while individual group guidelines may look very different, the principle of establishing the rules in advance is essential. Similarly, in relation to the important issue of grading, collaboratively establishing whether students will earn an individual or group grade, and what input they will have in terms of grading themselves or their peers, clarifies educational measurement. And, once the group work is underway. requiring early submissions of small pieces of the project, such as an outline for an academic paper, reveals potenfial problems.

The issue of non-contributing members is well represented in distance education literature addressing group work. 


\section{RESEARCH PAPERS}

Batos \& Poole (2003) stated that online leamers "object to group assignments on the grounds other students may not pull their weight" (p.237). Anderson \& Simpson (2004) asserted that "despite the value of small groups, students saw non-participation in groups as a major issue with the implications for workload, the value of learning activities, and motivation to continue engagement with the group ${ }^{x}$ (p.11). And, Collison, Elboum, Haavind \& Tinker (2000) declared that "ignoring the emotions parlicipants express can be deadening. Acknowledging and honoring them can break open now levels of communication, to the benefit and enrichment of the entise group" (p.98). In their online graduate study nursing classes, Dieklmann \& Mendias (2005) strive to make the issue more visible by demonstrating they know about non-contributing members and will connect with them by e-mail to comment on how their behavior affects others.

Therefore, knowing that this issue can be expected to exist in graduate study group work; implementing action strategies such as involving students in decisions about who will be in their small groups. what the rules will be and how they can participate in their grading process, must become a priority for educators.

\section{Conclusion}

This article presented findings from a descriptive research study that explored online graduate students' perceptions of issues they faced when working in small groups as well as instructional behaviors that can help to address these issues. In contrast to other studies that identified similar concerns with online group work, this project extends existing understanding by including health care professionals reflections on effective facilitation strategies. This research found that these professional leamers believed small group project work was more meaningful when instructors created their groups intentionally, intervened when members did not contribute and measured individual contributions. As the trend to inconporate small group projects in graduate study curticula continues to generate enthusiasm among educators, including the voices of students who have personal experience with this form of instruction becomes critical. This article calls for the creation and inclusion of more process oriented activities that listen to the issues students' face in online graduate study classrooms and the kinds of instructional responses they value.

\section{References}

Agostinho, S., Lefoe, G. \& Hedberg, J. (1997, July 6). Online collaboration for effective learning: A cose study of a postgraduate university course. Poper presented at the ThirdAustrolian World Wide Web Conference, Southern Cross University, Lismore, Australia. Retrieved on March 5,2006 from

Http://ausweb.scu.edu.au/proceedings/agostinh o/poper.htrml

Anderson, T. \& F. Elloumi, F. (Eds.) (2004). Theory and practice of online leaming. Athabasca, AB: Athabasca University Printing. Retrieved March 5. 2006, fromhittp//cde.athabascau.ca/online boo

Anderson, B. \& Simpson, M. (2004). Group and class contexts for learning and support online: learning andaffective support online in small group and class context. International Review of Research in Open o $n$ d Distance Leorning (IRRODL) Retrieved on March 5, 2006 from Www irrodl.org/content/v5.3/ander-simp.html

Bates, A.W. \& Poole, G. (2003). Effective teoching with technology in higher education. San Francisco: JosseyBass.

Chickering, A. W, and Gamson, Z. F (Eds.), (1991). Applying the Seven Principles for Good Practice in Undergraduate Education. New Directions for Teaching and Learning. no.47. San Francisco: Jossey-Bass.

Collison. G., Elbaum, B., Haavind, S. \& Tinker, R. (2000). 


\section{RESEARCH PAPERS}

Facilitating online learning: Effective strategies formoderators. Madison, Wl: Atwood.

Davis, B. G. (1993). Tools for teaching. San Francisco: Jossey-Bass.

Denzin, N.K., \& Lincoln, Y.S. (1994). Handbook of qualitotive research. Thousand Oaks, CA: Sage.

Diekelmann, N. \& Mendias, E. (2005). Being a supportive presence in online courses: Aftending to students' online presence with each other. Journal of Nursing Education, 44(9), 393-395.

Ehrlich, D.B. (2002). Establishing connections: Interactivity factors for a distance education course. Educational Technology \& Soclety 5(1), 48- 54.

Gabriel, M.A. \& MacDonald, C.J. (2002). Working together: the context of teams in an online MBA program. Cancodian Journal of Learning and Technology, 28(2), 4965. Retrieved on March 5, 2006 from

Http://Www.cjlt.ca/content/vol28.2/gabriel_mcdonal d.html

Hativa, N. \& Goodyear, P. (Eds.) (2002). Teacher thinking, beliefs and knowledge in higher education. Dordrecht: Kluwer.

Kearsley,G. \& Shneiderman, B. (1998). Engagement Theory: a framework for technology-based teaching and leaning. Educotional Technology, 38, 20-23.

Kelly, G. A. (1955). The psychology of personal constructs (2vols). New York: Norton.

Kreijns, K., Kirschner, P. \& Jochems, W. (2003). Identifying the pitfalls for social interaction in computersupported collaborative learning environments: A review of the research. Computers in Human Behovior, 19, 335 -
353.

Lincoln, Y.S. \& Guba, E.G. (1985). Noturalistic Inviry, Thousand Oaks, CA: Sage.

McKeachie, W.J. \& Hofer, B. (Eds) (2002). McKeachie's teaching tips: Strategies, research and theory for college and university teachers $\left(11^{\text {th }}\right.$ ed.) Boston: Houghton-Mifflin.

Melrose, S. (2006, in press). Facilitating help-seeking through student interactions in a WebCr online graduate study program. Journal of Nursing and Health Sciences.

Melrose, S. \& Bergeron, K. (2006, in press). Online graduate study health care leamers' perceptions of instructional immediacy. Intemational Review of Research In Open and Distance Learning (IRRODOL).

Melrose, S., Shapiro, B., LaVallie, C. (2005). Help-seeking experiences of health care learners in a Webcr online graduate study program. Canadian Journal of Learning and Technology: 31[2], 5-21.

Murray, M.H. \& Lonne, B. (2006). An innovative use of the web to build graduate team skills. Teaching in Higher Education, 11(1), 63-77.

Piaget, J. (1954). The construction of reaility in the child. New York: Basic Books.

Ramsden,P. (2003). Learning to teach in higher education (2nded.). London: Routledge-Falmer.

Vygotsky, L. (1978). Mind in society: The development of higher psychological processes. Cambridge, MA: Harvard University Press.

Acknowledgements

The authors wish to acknowledge funding from the Mission Critical Research Fund, Athabasca University.

\section{ABOUT THE AUTHORS}

Fuzirah Ms. Bergeron is a Graduate Student, Centre for Nursing and Health Studies and Research Assistant to Dr. Shern Melrose at Aithabasca University, Athabasca, Alberta, Canada

Dr. Melrose is an Assistant Professor, Centre for Nursing and Health Studies, Athabasca University, Alberta, who has published several articles on teaching and learning in online environments

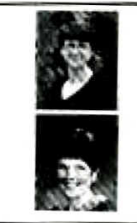

